\title{
Las visitas a los hogares pobres aumentan el intervalo entre embarazos y el bienestar materno
}

Enduring Effects of Nurse Home Visitation on Maternal Life Course. A 3-Year Follow-up of a Randomized Trial.

Kitzman H, Olds DL, Sidora K, Henderson ChR, Hanks C, Cole R, Luckey DW, Bondy J, Cole K, Glazner J. JAMA. 2000;283:1983-1989.

\section{Objetivo}

Determinar la efectividad de un programa prenatal e infantil de visitas al hogar sobre el período reproductivo de mujeres de un medio urbano.

\section{Diseño}

Estudio randomizado controlado con seguimiento de tres años. Los datos se analizaron con el modelo lineal generalizado para estudios longitudinales $^{1}$

\section{Lugar}

Las mujeres se incorporaron al programa en una maternidad de Memphis, Tenn, USA, entre junio de 1990 y agosto de 1991.

\section{Participantes}

Cohorte de 743 mujeres (724 negras y 19 blancas) embarazadas de menos de 29 semanas, sin hijos vivos anteriores y que presentaran al menos dos factores de riesgo social (ser soltera, haber recibido menos de 12 años de educación o estar desocupada).

\section{Intervención}

El grupo control $(n=443)$ recibió transporte gratuito para el control prenatal y del niño. El grupo intervención $(\mathrm{N}=203)$ recibió 7 (rango, 0 a 8) visitas domiciliarias durante el embarazo y 26 (rango 0 a 71) desde el nacimiento hasta el segundo año de vida del niño.

\section{Medición de los resultados principales}

Tasa de embarazos posteriores, intervalo promedio entre el primero y el segundo nacimiento, número promedio de meses de utilización de ayuda social.

\section{Resultados}

Las mujeres del grupo intervención tuvieron menos embarazos posteriores (1.15 a 1.34); menos casos con intervalos intergenésicos breves ( 0.22 vs 0.32 ) y mayores intervalos entre el primero y el segundo hijo (30.25 vs 26.6 meses), habiendo recibido ayuda social durante menos meses.

El efecto postintervención fue mayor sobre el espaciamiento de los embarazos y sobre la menor frecuencia de los mismos.

\section{COMENTARIO}

El efecto "buffer" del apoyo social sobre la pobreza tuvo mayor atención en las últimas décadas ${ }^{2}$. Los autores de este trabajo brindan evidencia empírica de la utilidad de esta intervención ya que enfermeras entrenadas pudieron ayudar a las mujeres a espaciar y disminuir significativamente sus embarazos. Estos resultados están relacionados con acciones de planificación familiar. Cabe destacar que las intervenciones que tratan de modificar los hábitos maternos (tabaco, drogas) o resultados feto-neonatales (bajo peso, prematurez, lactancia) durante el embarazo parecen estar destinadas al fracaso. Sin embargo, se considera que el intervalo intergenésico (del que no existen registros en el país) es la variable más importante y compleja relacionada con la sobrevida de un niño ${ }^{3}$.

El diseño usado en este estudio tiene la robustez metodológica su- ficiente como para concluir que las mejoras observadas se asocian con el apoyo social (ej. transporte gratis en ambos grupos). Otros estudios similares también llegaron a las mismas conclusiones. Como dijimos, hay mucha experiencia sobre la utilidad de visitadores familiares durante el embarazo y posparto en países desarrollados y subdesarrollados. En Argentina esto se hace en algunas regiones a través de iniciativas locales que se mantienen solo gracias a la buena voluntad de su personal de salud y de voluntarios. Parecería adecuado comenzar a implementar este tipo de estrategia en forma orgánica, para que el personal de salud que asiste madres y niños salga de las instituciones y visite los hogares para realizar acciones de promoción y prevención.

Dr. Jorge Vinacur

Maestría en Salud Pública. Universidad de Buenos Aires

\section{Referencias}

1. Dwyer JH, et al. Statistical Models for Longitudinal Studies of Health. New York: Oxford Univ. Press; 1992:198.

2. Klerman LV, Merkatz IR. Maternity-related health care in the USA. In Sachs BP et al, eds. Reproductive Health Care for Women and Babies. New York: 0xford Univ. Press; $1995: 207-221$. 3. Vinacur JC, et al.: Intervalo interembarazo o intercenésico, Rev de S0GIBA, en prensa, 2000. 